\title{
Plasma uric acid and plasma albumin in healthy subjects
}

\author{
LAWRENCE RAMSAY, THERESA MITCHELL, AND JOHN SHELTON
}

From the Departments of Medicine and Biochemistry, Western Infirmary, Glasgow, and Division of Scientificc Affairs, G. D. Searle and Co., High Wycombe, Bucks.

SUMMARY In healthy male subjects there was a positive correlation between plasma uric acid aind plasma albumin $(r=0.43, P<0.005, n=49)$ when repeated measurements of both variables were used for each subject. Changes in plasma albumin induced by in vivo ultrafiltration were nt accompanied by changes in plasma uric acid. The correlation of plasma uric acid with plasnifa albumin cannot be attributed to protein binding of urate. The two variables are probably related indirectly through a common association with an unknown factor or factors.

Studies of protein binding of uric acid have been hampered by problems with in vitro methodology, and by difficulty in relating the results of in vitro studies to the physiological situation. Reviewing the literature, Gutman and Yu (1972) concluded that binding of urate to plasma proteins in vivo was so small as to have negligible physiological implications. However, reports have continued to appear suggesting that up to $20 \%$ of uric acid may be protein bound (Campion et al., 1973, 1974; Postlethwaite et al., 1974; Kippen et al., 1974a). A significant development was evidence that uric acid was protein bound in vivo and could be displaced by salicylate (Postlethwaite et al., 1974), although Farrell et al. (1975) were unable to confirm these findings. The question has assumed added importance after the suggestion that uricosuric agents may act by displacing uric acid from binding sites on protein, thus increasing the renal clearance of urate (Kippen et al., 1974b; Kelley, 1975).

Acheson and Chan (1969) and Roberts (1972) have shown weak positive partial correlations between plasma uric acid and plasma albumin in populations of healthy subjects, and Roberts (1972) thought that this was probably attributable to protein binding of uric acid. The objectives of our first study were to confirm this relationship, and to determine whether it was strengthened by using repeated measurements of the two variables for each

Accepted for publication November 22, 1976

Correspondence to Dr. L. E. Ramsay, Department of Medicine, Gardiner Institute, Western Infirmary, Glasgow G11 6NT subject. Subsequently we studied changes in plasiga uric acid in healthy subjects in whom increases in plasma albumin were induced by in vivo ultrafilttation (van Leeuwen, 1964).

\section{Patients and methods}

In the first study we examined retrospectively data for 49 males aged $18-55$ years who had been judged healthy after medical history, examination, a\#d biochemical and haematological screening. Repeated simultaneous measurements of plasma uric acid and plasma albumin (mean 6.4 estimates per subjeet, range 3-15 estimates) were available for each subject. Blood was drawn at 9.00 am after the subjects had avoided all forms of medication forcat least 5 days, and alcohol for 24 hours. Sampling was usually at one-week intervals. The subjects had been studied as 6 separate groups. The mean of all measurements of plasma uric acid and plas albumin for each subject was calculated, giving single estimate for each subject which will ofe referred to as the 'usual' plasma uric acid and albumin concentrations.

In the second study in 6 healthy subjects in vivo ultrafiltration using tourniquet compression of the arm, as described by van Leeuwen (1964), wiens performed. The subjects were recumbent with boith arms resting on the bed throughout the procedure. Sphygmomanometer cuffs were applied to both upper arms and inflated to a pressure midwळy between the systolic and diastolic blood pressures Venous blood for measurement of plasma uric acia, albumin, total protein, calcium, and magnesium was 
drawn from the first arm after 5 minutes' compression, and the cuff was deflated. A similar sample was taken from the other arm after 15 minutes' compression, and the second cuff was deflated. A third (resting) sample was drawn without venous statis from the first arm at least $\mathbf{3 0}$ minutes after the cuff had been deflated. The resting sample was taken at this time to avoid haematoma formation during tourniquet compression.

\section{LABORATORY INVESTIGATIONS}

In the first study plasma uric acid had been measured by a nonspecific colorimetric method (Nishi, 1967) with a coefficient of variation between batches of approximately $4 \%$. In the second study uric acid was measured by a specific uricase method using the Beckman glucose analyser.

Albumin was measured by automated methods (first study: Nishi and Rhodes, 1965; second study: Doumas et al., 1971), and calcium and magnesium by atomic absorption spectrophotometry. In the second study the three samples for each subject were assayed within a single batch to remove any effect of laboratory variation between batches. The statistical procedures used (product moment correlations, comparison of correlation coefficients, calculation of the average correlation coefficient, and Student's $t$ test for paired observations) are described by Armitage (1971) and Pearson and Hartley (1966).

\section{Results}

URIC ACID AND ALBUMIN: BETWEEN-SUBJECT RELATIONSHIP

In the 49 subjects the usual plasma uric acid concentration ranged from $0 \cdot 238-0.484 \mathrm{mmol} / \mathrm{l}(2 \cdot 5-$ $8 \cdot 1 \mathrm{mg} / 100 \mathrm{ml}$ ), and the usual albumin from $40 \cdot 0-48 \cdot 5 \mathrm{~g} / \mathrm{l}$. The two variables correlated weakly, but highly significantly $(\mathrm{r}=+0 \cdot 43, \mathrm{P}<0 \cdot 005, \mathrm{n}=49$; Fig.). Comparison of the correlation coefficients for the six subgroups showed that they did not differ significantly, allowing calculation of the average correlation coefficient. This method ensures that combination of the data from different groups had not introduced bias. The correlation was in fact strengthened by this method $(\mathrm{r}=+0 \cdot 58, \mathrm{P}<0 \cdot 001)$.

\section{IN VIVO ULTRAFILTRATION}

The mean and standard error results for all variables in the 6 subjects are shown in Table 1 , and the individual results for plasma uric acid in Table 2. Tourniquet compression for 15 minutes produced highly significant increases in total protein (mean $+39 \%, P<0.001)$ and plasma albumin $(+39 \%$, $\mathrm{P}<0.001)$. The range of plasma albumin concentrations observed in this study (39-66 g/l) far exceeded that in the first study $(40-48 \cdot 5 \mathrm{~g} / 1)$. Serum calcium $(+15 \%, \quad P<0.001)$ and magnesium $(+17 \%$, $\mathbf{P}<0.001)$ also showed significant increases after 15 minutes' compression. In contrast, plasma uric acid concentration did not alter significantly during the experiment, nor was any trend to increase evident.

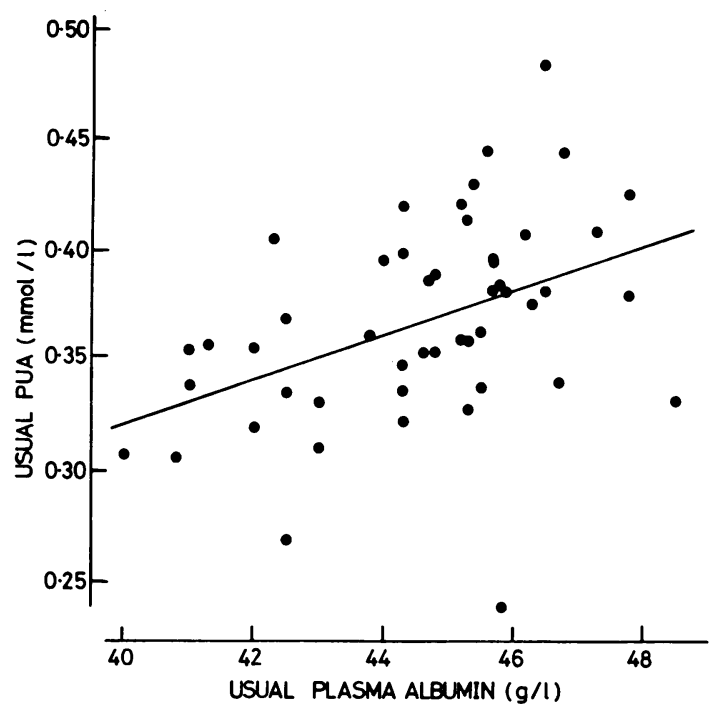

Fig. Correlation between the usual plasma uric acid (PUA) concentration and usual plasma albumin in 49 healthy males $(r=+0 \cdot 43, P<0 \cdot 005)$.

Table 1 Mean $( \pm S E M)$ results in 6 subjects for plasma variables measured without tourniquet compression and at 5 and 15 minutes during compression

\begin{tabular}{|c|c|c|c|}
\hline & \multicolumn{3}{|c|}{ Duration of compression (min) } \\
\hline & 0 & 5 & 15 \\
\hline Albumin (g/l) & $40 \cdot 5 \pm 0 \cdot 67$ & $48 \cdot 8 \pm 1 \cdot 89 \dagger$ & $56 \cdot 2 \pm 2 \cdot 26 \ddagger$ \\
\hline Total protein $(\mathrm{g} / \mathrm{l})$ & $69 \cdot 3 \pm 1 \cdot 35$ & $83 \cdot 5 \pm 3 \cdot 00 \dagger$ & $96 \cdot 5 \pm 3 \cdot 96 \ddagger$ \\
\hline Uric acid (mmol/1) & $0.345 \pm 0.018$ & $0.345 \pm 0.020$ & $0.345 \pm 0.017$ \\
\hline Calcium (mmol/l) & $2 \cdot 30 \pm 0.036$ & $2 \cdot 54 \pm 0.078^{*}$ & $2.65 \pm 0.025 \ddagger$ \\
\hline Magnesium (mmol/l) & $0.78 \pm 0.022$ & $0.90 \pm 0.012 \dagger$ & $0.91 \pm 0.015 \ddagger$ \\
\hline
\end{tabular}

$* \mathbf{P}<0.02 ; \dagger \mathbf{P}<0.01 ; \ddagger \mathbf{P}<0.001$ versus zero compression. Conversion: SI to traditional units-Uric acid: $1 \mathrm{mmol} / 1 \approx 16.8 \mathrm{mg} /$ $100 \mathrm{ml}$. Calcium: $1 \mathrm{mmol} / \mathrm{l} \approx 4 \mathrm{mg} / 100 \mathrm{ml}$. Magnesium: $1 \mathrm{mmol} / 1 \approx$ $2.4 \mathrm{mg} / 100 \mathrm{ml}$.

Table 2 Individual results in 6 subjects for plasma uric acid (mmol/l) during tourniquet compression

\begin{tabular}{llll}
\hline \multirow{4}{*}{ Subject } & \multicolumn{3}{l}{ Duration of compression (min) } \\
\cline { 2 - 4 } & 0 & 5 & 15 \\
\hline 1 & 0.36 & 0.36 & 0.35 \\
2 & 0.34 & 0.33 & 0.36 \\
3 & 0.31 & 0.29 & 0.31 \\
4 & 0.30 & 0.31 & 0.29 \\
5 & 0.34 & 0.35 & 0.35 \\
6 & 0.42 & 0.43 & 0.41 \\
Mean (SEM) & $0.345(0.018)$ & $0.345(0.020)$ & $0.345(0.017)$ \\
\hline
\end{tabular}




\section{Discussion}

The results of our first study confirm the betweensubject partial correlations of uric acid and albumin previously reported in healthy populations by Acheson and Chan (1969) and Roberts (1972). The correlation coefficient was considerably higher in the present study presumably because repeated measurements were made in each subject, a procedure tending to minimize the effect of any day-to-day variation within subjects and in the laboratory. From the average correlation coefficient $(r=+0.58)$ it can be calculated that $34 \%\left(r^{2} \times 100\right)$ of the variation in plasma uric acid between subjects can be related to differences in plasma albumin. If Roberts's (1972) postulate that the correlation arises from protein binding of uric acid was correct, then $34 \%$ of the intersubject variance in plasma uric acid could be attributed to protein binding.

To test the hypothesis further we sought a method to study protein binding of uric acid in vivo, bearing in mind the controversy which has arisen from in vitro studies (Gutman and Yu, 1972; Kippen et al., 1974b). Postlethwaite et al. (1974) and Farrell et al. (1975) have used haemodialysis for this purpose, but the results from the two groups were not in agreement. The use of haemodialysis also has the disadvantage of being restricted to study of patients with renal failure. The technique of in vivo ultrafiltration using tourniquet compression has been thoroughly evaluated by van Leeuwen (1964) and has been used to study the protein binding of various endogenous substances such as calcium and magnesium (Berry et al., 1973; Pain et al., 1975) and thyroid hormones (Judd et al., 1975). We could find no report of measurement of plasma uric acid during in vivo ultrafiltration, and adopted this approach to the problem. Measurements of plasma calcium and magnesium were included to give some estimate of the sensitivity of the experiment. Approximately $41 \%$ of total calcium and $33 \%$ of total magnesium are bound to plasma protein (van Leeuwen, 1964).

The study conditions were sensitive enough to show the expected changes in calcium and magnesium at a high level of significance. In contrast, plasma uric acid showed no change during tourniquet compression, without even a trend to increase. Extrapolating from the between-subject regression of uric acid on albumin in our first study, a rise in plasma uric acid of $0.14 \mathrm{mmol} / 1$ would have been anticipated from the changes in plasma albumin observed after 15 minutes' compression. Clearly this did not occur. From their experimental observations Postlethwaite et al. (1974) divided subjects into 'binders' and 'non-binders' of uric acid. Inspection of the individual results (Table 2 ) does not suggest that any of our 6 subjects were 'binders'. The maximal increase in plasma uric acid in any ind vidual during compression was $6 \%$, and only on subject had a consistent rise (of $3 \%$ ) at both sampling times. The error of the method can easily explaing these variations.

Van Leeuwen (1964) has examined the changes i⿱ venous blood during in vivo ultrafiltration and apart from changes in protein and protein-bound substances, the only change of possible relevance in the present context was in $\mathrm{pH}$. Uric acid is a weats acid and its distribution in body fluids may be influenced by the phenomenon of nonionic diffusiog (Zweifler and Thompson, 1965). The conditions used in our study are associated with average fals of venous blood $\mathrm{pH}$ of 0.04 (van Leeuwen, 1964) Since this change is secondary to intracellular p change, the intracellular $\mathrm{pH}$ will fall to a similar, of greater, degree. If any pH-related shift of uric acid between the intracellular and extracellular compare ments does occur, one would expect it to raise plasma uric acid. We conclude that a rise in plasme uric acid due to protein binding would not be disguised by $\mathrm{pH}$ changes during compression.

It remains to explain why plasma uric acid and albumin show a significant correlation betweel subjects, but no relationship during tournique ultrafiltration. In the latter study we used the specific uricase method for uric acid, while the urio acid-albumin correlation in the present study and in those of Acheson and Chan (1969) and Roberts (1972) was shown using nonspecific colorimetric methods. It is therefore possible that the between subject correlation is caused by protein binding of nonurate chromogens, but this seems improbable 谓 a population of subjects taking no medication. f this possibility is discounted then it is clear from the present studies that the between-subject correlation cannot be attributed to protein-binding of uric acia or indeed to any other direct causal relationship of the two variables. Rather, plasma uric acid and albumin are related in the population through songe other factor in such a way that they can var, independently during ultrafiltration. Recalling tha $34 \%$ of the variation in plasma uric acid betweeng subjects can be accounted for in terms of plasmg albumin, the nature of the factor linking the twe variables is clearly of some importance. Acheson and Chan (1969) suggested in general terms that the relationship may depend on nutritional status. \& further possibility is that plasma albumin and urie acid may be related through the extracellular fluid volume. In acute situations plasma albumin concer tration and plasma uric acid (Steele, 1969) show changes in a similar direction with changes if extracellular volume. It has been suggested that the 
usual plasma uric acid concentration in healthy subjects may be determined to some extent by the customary dietary intake of sodium, the latter influencing extracellular fluid volume (Ramsay et al., 1975). If the usual plasma albumin is similarly influenced, then the correlation observed could be explained on this basis.

In conclusion we have shown a moderate correlation between plasma uric acid and plasma albumin in healthy subjects. Data obtained during in vivo ultrafiltration do not suggest that they are related through protein binding of uric acid, nor do they support the contention that urate is protein bound to any important degree. Study of the mechanism underlying the relationship between uric acid and albumin might prove helpful in explaining the wide differences in plasma uric acid between healthy subjects.

\section{References}

Acheson, R. M., and Chan, Y. K. (1969). New Haven survey of joint diseases. The prediction of serum uric acid in a general population. Journal of Chronic Diseases, 21, 543-553.

Armitage, P. (1971). Statistical Methods in Medical Research. Blackwell, Oxford.

Berry, E. M., Gupta, M. M., Turner, S. J., and Burns, R. R. (1973). Variations in plasma calcium with induced changes in plasma specific gravity, total protein, and albumin. British Medical Journal, 4, 640-643.

Campion, D. S., Bluestone, R., and Klinenberg, J. R. (1973). Uric acid. Characterization of its interaction with human serum albumin. Journal of Clinical Investigation, 52, 2383-2387.

Campion, D. S., Bluestone, R., and Klinenberg, J. R. (1974). Displacement by uricosuric agents of sodium urate bound to human serum albumin. Biochemical Pharmacology, 23, 1653-1657.

Doumas, B. T., Watson, W. A., and Biggs, H. G. (1971). Albumin standards and the measurement of serum albumin with bromocresol green. Clinica Chimica Acta, 31, 87-96.

Farrell, P. C., Ward, R. A., and Hone, P. W. (1975). Uric acid: binding levels of urate ions in normal and uraemic plasma, and in human serum albumin. Biochemical Pharmacology, 24, 1885-1887.
Gutman, A. B., and Yu, T. F. (1972). Renal mechanisms for regulation of uric acid excretion, with special reference to normal and gouty men. Seminars in Arthritis and Rheumatism, 2, 1-46.

Judd, S. J., Carter, J. N., and Corcoran, J. M. (1975). Circulating thyroid hormone concentrations and posture and venous compression. British Medical Journal, 4, 735-736.

Kelley, W. N. (1975). Effects of drugs on uric acid in man. Annual Review of Pharmacology, 15, 327-349.

Kippen, I., Klinenberg, J. R., Weinberger, A., and Wilcox, W. R. (1974a). Factors affecting urate solubility in vitro. Annals of the Rheumatic Diseases, 33, 313-317.

Kippen, I., Whitehouse, M. W., and Klinenberg, J. R. (1974b). Pharmacology of uricosuric drugs. Annals of the Rheumatic Diseases, 33, 391-396.

Leeuwen, A. M. van (1964). Net cation equivalency (base binding power) of the plasma proteins. A study of ionprotein interaction in human plasma by means of in vivo ultrafiltration and equilibrium dialysis. Acta Medica Scandinavica, 176, Suppl. 422.

Nishi, H. H. (1967). Determination of uric acid. An adaptation of the Archibald method on the autoanalyser. Clinical Chemistry, 13, 12-18.

Nishi, H. H., and Rhodes, A. (1965). An automated procedure for the determination of albumin in human serum. Automation in Analytical Chemistry, p. 321. Technicon Symposia. Mediad, New York.

Pain, R. W., Rowland, K. M., Phillips, P. J., and Duncan, B. McL. (1975). Current corrected calcium concept challenged. British Medical Journal, 4, 617-619.

Pearson, E. S., and Hartley, H. O. (1966). Biometrika Tables for Statisticians, Vol. 1, 3rd. ed. Cambridge University Press, London.

Postlethwaite, A. E., Gutman, R. A., and Kelley, W. N. (1974). Salicylate-mediated increase in urate removal during haemodialysis: evidence for urate binding to protein in vivo. Metabolism, 23, 771-777.

Ramsay, L. E., Auty, R. M., Horth, C. E., Levine, D., Shelton, J. R., and Branch, R. A. (1975). Plasma uric acid concentration related to the urinary excretion of aldosterone and of electrolytes in normal subjects. Clinical Science and Molecular Medicine, 49, 613-616.

Roberts, L. B. (1972). Partial correlation of some blood constituents. Clinical Chemistry, 18, 1407-1410.

Steele, T. H. (1969). Evidence for altered renal urate reabsorption during changes in volume of the extracellular fluid. Journal of Laboratory and Clinical Medicine, 74, 288-299.

Zweifler, A. J., and Thompson, G. R. (1965). Correction of thiazide hyperuricaemia by potassium chloride and ammonium chloride. Arthritis and Rheumatism, 8, 1134 1144. 